\title{
Automatic road traffic safety management system in urban areas
}

\author{
Jacek Oskarbski ${ }^{*}$ \\ ${ }^{1}$ Gdansk University of Technology, Faculty of Civil and Environmental Engineering, Gdansk, Poland
}

\begin{abstract}
Traffic incidents and accidents contribute to decreasing levels of transport system reliability and safety. Traffic management and emergency systems on the road, using, among others, automatic detection, video surveillance, communication technologies and institutional solutions improve the organization of the work of various departments involved in traffic and safety management. Automation of incident management helps to reduce the time of a rescue operation as well as of the normalization of the flow of traffic after completion of a rescue operation, which also affects the reduction of the risk of secondary accidents and contributes to reducing their severity. The paper presents the possibility of including city traffic departments in the process of incident management. The results of research on the automatic incident detection in cities are also presented.
\end{abstract}

\section{Introduction}

Transport systems are a key element in meeting basic social needs related to population mobility and supplies. They facilitate the development of economic activity and contribute to upgrading the quality of life. Society expects a high level of reliability of transport while traveling to work, schools and for recreation. Today, however, it is already known that certain changes in transport management are necessary to tackle such urgent problems as traffic congestion, environmental pollution, traffic safety or social risks, at the same time ensuring sufficient mobility in the future. The development of Intelligent Transportation Systems (ITS) as supplementary to long-term measures in transport policy offer hope for at least a partial solution to the problems encountered, including in particular the problem of transport safety. Consequently, many cities in developed countries introduce intelligent systems of transportation management. The intensified implementation of ITS services has also been observed in Polish towns and on rural roads for several years now. Traffic services are not the sole beneficiaries of such ITS services. New software and hardware solutions are also applied by institutions participating in rescue operations (medical services, fire brigades) and preventive actions (e.g. those related to speed control). Systems used by road authorities as well as emergency and preventive services provide detailed data on traffic incidents and other big data which can be used at planning and operational levels of security management. These data are also a potential resource that could be the basis for research aimed at improving and developing new methods and means to upgrade traffic safety. Changes taking place through technological development, that manifest themselves in an ever wider use of automation in transportation processes, justify the revision of the current approach to traffic safety

*Corresponding author: joskar@pg.gda.pl 
management in order to strengthen the integration of services and to develop procedures for their cooperation.

\section{Traffic safety management system}

\subsection{System components}

According to the definition the "transportation system" is a system of technical, organizational and human resources, combined with one another in such a way that it can efficiently carry out the traffic of people and goods in space and time [1]. In the system of traffic safety management, which is inextricably linked to the transportation system, we can identify many interrelated and mutually interacting elements:

- structures of organization of traffic safety management services, as well as legal bases and procedures that determine the organization, competences and collaboration of such services, - tools influencing the improvement of traffic safety management at the strategic level (e.g. regional, local and sectoral programs of traffic safety management, including monitoring of their implementation) and the operational level (current monitoring and supervision),

- broader support tools for system management (e.g. databases, information systems, expert systems, guidelines and examples of good practice, ITS services) based on scientific research,

- management methods for the whole system and its selected elements (including risk management).

The National Road Safety Program for 2013-2020 [2] indicated that the process of improving traffic safety requires the use of up to three consecutive and interlinked components: institutional management functions, specific actions (interventions) and outcomes. Basic functions of institutional management included coordination, legislation, financing and provision of resources, promotion and communication, monitoring and evaluation, as well as research, development and knowledge transfer.

The diagnosis of the existing system of safety management carried out in the framework of the National Road Safety Program has shown that each of these functions needs to be improved in terms of implementation of measures included in the Program. These functions are performed in different proportions depending on the particular institution and the level of public administration. They highlighted the need to improve organizational structures of traffic safety and coordination with the National Road Safety Council as a leading institution, as well as with Regional Road Safety Councils as the real leaders of the region - with the support of research institutions. Regional Road Safety Councils should perform management functions, among others, in terms of horizontal coordination - between regional structures of the Police, Road Transport Inspectorate, State Fire Service, the General Directorate for National Roads and Motorways, regional roads authorities, county roads authorities, the school superintendent, local NGOs and local communities, as well as through vertical coordination - with the National Road Safety Council and county road safety councils [2]. The representation of such a broad body in the works of road safety councils provides an opportunity to develop conclusions regarding necessary legislative changes and investigating the needs of cooperation in the management of traffic safety at the level of use of technology and databases as well as their integration, which may result in modification and development of new procedures for cooperation between the services. An example of new work on the introduction of a uniform system of monitoring and communication is the Polish Road Safety Observatory, functioning at the Motor Transport Institute, and emerging regional observatories. Equally important is also gathering data on traffic parameters that - when compared with data on traffic incidents - can be helpful in developing methods for improving 
traffic safety. Such data can be collected, for instance, in ITS Regional Laboratories. The structures of these databases and their linkages should be developed. It is also important to ensure universal access to data. The activities of local governments working on solutions in the field of "Smart City" can be helpful in this respect. The result of these activities should be the introduction of traffic safety and knowledge transfer.

\subsection{Operational traffic safety management}

The system of transport suffers disruptions every day. Transport systems become less reliable (which in particular affects the reliability of travel time within a transport network) [3] when undesired incidents take place. These include dangerous incidents (accidents and collisions) and incidents (such as a vehicle becoming stationary due to a breakdown or driver indisposition, objects on the road, failure of parts of road infrastructure) [4]. This suggests that a systemic solution is required to help restore normal traffic conditions faster after the accident scene is cleared and minimize travelers' time lost. The objective is also to reduce the risk of secondary events (by keeping motorists informed about the incident and controlling speed via Variable Message Signs) and accident severity (by reducing the time for emergency services to get to the scene and attend to the casualties). With the deployment of ITS services in Poland the work of the services can now be intensified and integrated as part of operational road safety management. The architecture of the Tri-City's Integrated Traffic Management System TRISTAR provides for the delivery of an operational road safety management system as depicted in Fig. 1.

Traffic Incident Management (TIM) is a systematic, planned and coordinated use of resources to reduce the impact of incidents, and improve the safety of motorists, crash victims and incident responders and to restore normal traffic conditions after the occurrence of an incident is detected on the road. Using its detection capability, the Monitoring and Traffic Surveillance System supports the collection of data about traffic parameters, weather conditions, travel times on specific street sections. Once processed they can be used by Traffic Safety Management System modules. The Automatic Supervision of Drivers Behavior Module is designed to detect road traffic offences such as exceeding momentary speed and average speed on a road section and driving over the STOP line on a junction or pedestrian crossing on a red light for the particular direction. At present, the modules collect offence statistics, a useful source of information for road authorities when they take steps to improve traffic layout and for the police when they take preventive action. The data can be used to send complete sets of offence information to a central traffic enforcement body. Before drivers can be punished for offences they have committed, the law and organizational arrangements must be revised and verified. The next task of the module is to pass on travel time information for use in the Traveler Information System (drivers can access the information via VMS and website) [5].

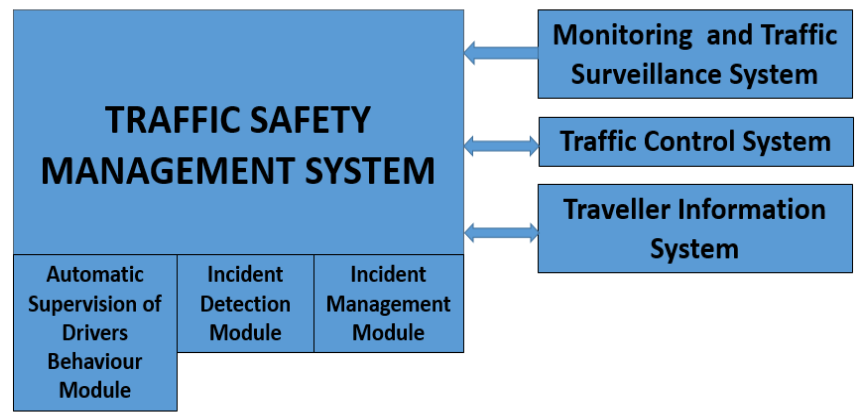

Fig. 1. Traffic safety management in TRISTAR system. 
In the case of the Incident Detection Module - a pilot implementation of the first element of the module has been completed. The project enables automatic detection of traffic incidents on a few selected street sections in the Tri-City (a dual carriageway with 2 lanes in each direction, Polish class of street - GP), e.g. on Gdynia's Kwiatkowski Route. The main element of the data processing module are algorithms that analyze available data to detect incidents. The module uses data from Bluetooth and Wi-Fi scanners that detect Bluetooth or Wi-Fi devices (mobile phones, smartphones, tablets, computers and in-vehicle devices to support hands-free systems - e.g. in-car speaker phones). The data collected by each pair of scanners (located at the beginning and end of the road section) are used to calculate travel times on defined distances between scanners. An algorithm based on Kalman filter is used to verify the data transmitted from the network of scanners [6]. The incident detection algorithm checks the changes in travel time between measuring points every minute and when a sudden and unjustified change in travel time occurs, a notification is sent to the system operator with proposed information to be displayed on VMS [7],[8]. This is how the Incident Management Module goes into operation. It can start a traffic management strategy if there is an incident. It uses the Traveler Information System (warnings displayed on VMS about an incident, detours, road closure, speed management) and the Traffic Control System (change in signalization programs in response to a change in traffic distribution on the street network).

\section{Effects of using ITS services for operational road safety management}

When there is a road accident, the victim may suffer serious injury leading to their death or disability, unless help is provided without delay. A fast response by emergency services may substantially increase the chance of survival and reduce long-term consequences of the trauma. According to the principle of the "golden hour" the lives of $20-40 \%$ of seriously injured casualties can be saved, if they receive hospital treatment within 60 minutes from the event. They are the more likely to live, the sooner they receive first aid at the scene (within "ten golden minutes") before they are taken to hospital. European research estimates that transport telematics can reduce the response time and intervention of emergency services by as much as $30 \%$ [9]. When an incident is detected and verified, a strategy is activated which should ensure that a rescue team is quickly put together and the necessary equipment is made available. The response to an incident includes dispatching services to the scene. The steps should also include informing motorists once it is certain that the accident happened. Fast response to incidents means that the appropriate services must take action immediately. To speed up the process of detecting dangerous incidents, automatic incident methods can be used. If detected early, the incident will have a shorter duration and getting help to the casualties will take less time. As a result, accident severity will be reduced and the time of exposure to risk of secondary incidents will be minimized. Travelers' time lost will also be minimized [10],[11]. Other benefits include a reduction in serial and secondary incidents (up to $29 \%$ ), drivers' working time, fuel consumption and emissions [12],[13]. The majority of the city algorithms were developed to detect incidents on sections of the arterial road between junctions and some of them support detection on junctions. Under the CIVITAS DYN@MO project algorithms were developed using time series and artificial neural networks that can detect an incident on signalized junctions [8], [14]. Fig. 2 shows an example of an incident detection using the algorithms - the FiltrLP model. The model signalizes differences in current trend, speed measured at a control point PK_0 (traffic measurement station) and the "normal" trend, i.e. the trend on a day that is similar to the day in question on which there were no incidents. 


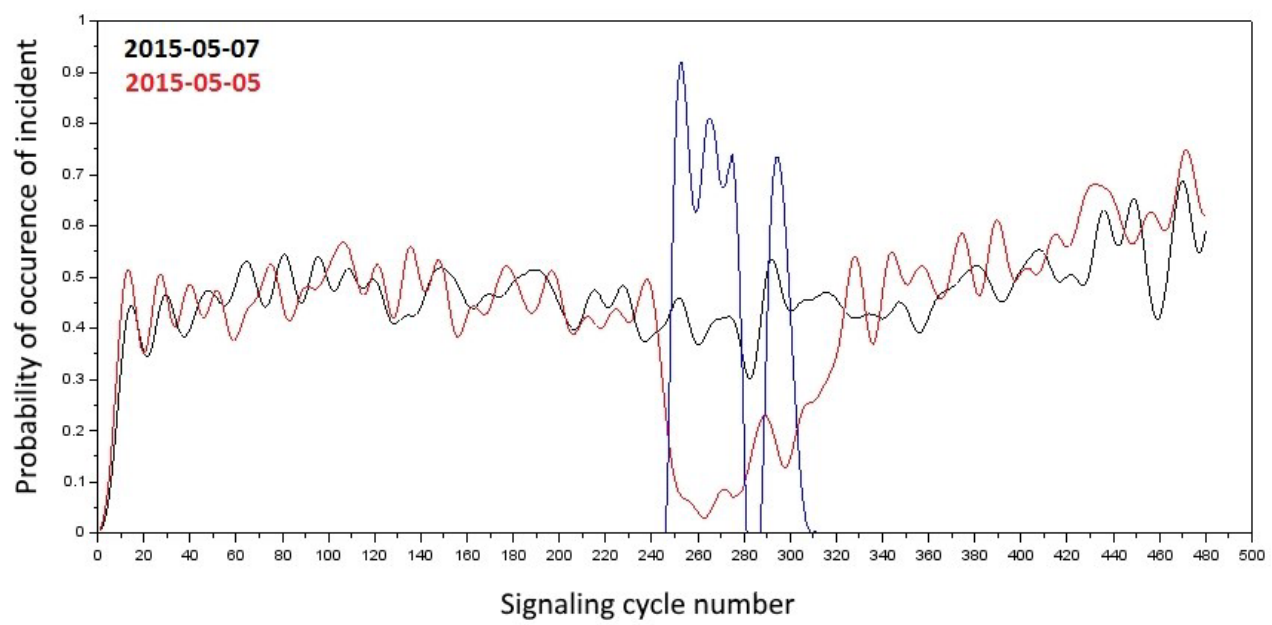

Fig. 2. Answer of the model (blue) - the probability of occurrence of the incident on 2015-05-05 established on the basis of the difference in trends ranks PK_0_V on 2015-05-07 (black) and 201505-05 (red).

\section{Conclusions}

With new ITS services deployed in Polish cities and on national roads in recent years, it is possible to improve the traffic safety system at the strategic (planning) and operational level. There is an increasing number of databases that store big data from integrated transport management systems. These should be integrated and made available as Open Data to improve ITS services and applications to stimulate the emergence of new ones. If the data from the databases can be analyzed, new methods and tools for analyzing road safety can be created. The system of safety monitoring in real time and over extended periods can improve as a result. With data stored in a single system, they can be integrated and used in applications for exchanging data between stakeholders. Once processed, the data can be presented on an information platform (it would be useful to integrate IT systems and databases of the relevant services to ensure data security and controlled access to sensitive data). An important step towards improving the flow of information and notifying the services is the National Access Point deployed by the General Directorate for National Roads and Motorways. ITS resources can also be used to support cooperation between emergency and preventive services with traffic control. This, however, will require new procedural and equipment standards (to ensure equipment compatibility and communications) at the national level including the local specificity and stakeholders involved in incident management and inclusion in the system of Traffic Management Centers. The first procedures of cooperation between emergency services and road authorities were developed as part of Rescue Plans for motorways and express roads. There is opportunity to disseminate these procedures as the National Traffic Management System (KSZR) is developing. The procedures should also be implemented in cities that already have integrated ITS solutions. One of the main steps towards a successful improvement of the road safety management system is developing clear legal bases and verifying the existing ones. 


\section{Acknowledgements}

Scientific study financed from funds for science in the years 2013-2016 granted to an international project co-financed within the CIVITAS DYN@MO project.

\section{References}

1. M. Jacyna, Wybrane zagadnienia modelowania systemów i procesów transportowych (Oficyna Wydawnicza Politechniki Warszawskiej, 2009)

2. National Road Safety Programme for 2013-2020 (Polish National Road Safety Council, Warsaw, Poland, 2013)

3. J. Oskarbski, K. Jamroz, Reliability and Safety as an Objective of Intelligent Transport Systems in Urban Areas, J. KONBiN. 2 pp. 59-70 (2015)

4. K. Jamroz, A. Kadziński, A. Szymanek, K. Chruzik, L. Gucma, J. Skorupski, Integracja metod zarządzania ryzykiem w transporcie, in: Zintegr. Syst. Bezpieczeństwa Transp. Tom 2 Uwarunk. Rozw. Integr. Syst. Bezpieczeństwa Transp., (2009)

5. J. Oskarbski, M. Zawisza, M. Miszewski, Information System for Drivers Within the Integrated Traffic Management System - TRISTAR, in: Commun. Comput. Inf. Sci. Vol. 531, pp. 131-140 (2015)

6. J. Barcelo, L. Montero, M. Bullejos, O. Serch, C. Carmona, A Kalman filter approach for exploiting Bluetooth traffic data when estimating time-dependent OD matrices, J. Intell. Transp. Syst. Technol. Planning, Oper. 17 pp. 123-141 (2013)

7. J. Oskarbski, Perspectives of Telematics Implementation in Tri-City Transport Systems Management and Planning, in: Commun. Comput. Inf. Sci. Vol. 239, pp. 233-240 (2011)

8. J. Oskarbski, M. Zawisza, K. Żarski, Automatic incident detection at intersections with use of telematics, in: Transp. Res. Procedia Vol .14, pp. 3466-3475 (2016)

9. M. McDonald, H. Keller, J. Klijnhout, V. Mauro, R. Hall, A. Spence, C. Hecht, O. Fakler, Intelligent Transport Systems in Europe. Opportunities for Future Research, World Sci. (2006)

10. K.J. Button, D.A. Hensher, L. Schintler, Handbook of Transport Systems and Traffic Control (Pergamon, 2001)

11. J. Oskarbski, Automatyzacja zarządzania zdarzeniami drogowymi, Drogownictwo. 4 pp. 153-156 (2012)

12. G.L. Chang, S. Rochon, Performance Evaluation and Benefit Analysis for CHART in Year 2007, Final report (2007)

13. Analytical procedures for determining the Impacts of Reliability Mitigation Strategies, SHRP2 Reliability Research, Report S2-LO3-RR-1 (Transportation Research Board, 2013)

14. J. Oskarbski, K. Palikowska, K. Żarski, Systemy automatycznego wykrywania zdarzeń niepożądanych w miastach, Pr. Nauk. Politech. Warsz. Transp. 114 pp. 245-254 (2016) 